\title{
K-Band Radio frequency Interference Survey of Southeastern Michigan
}

Curry, Shannon; Ahlers, Michael Faursby; Elliot, Harvey; Gross, Steve; McKague, Darren; Misra, Sidarth; Puckett, John; Ruf, Chris

Published in:

International Geoscience and Remote Sensing Symposium proceedings

Link to article, DOI:

10.1109/IGARSS.2010.5649435

Publication date:

2010

Document Version

Publisher's PDF, also known as Version of record

Link back to DTU Orbit

Citation (APA):

Curry, S., Ahlers, M. F., Elliot, H., Gross, S., McKague, D., Misra, S., Puckett, J., \& Ruf, C. (2010). K-Band Radio frequency Interference Survey of Southeastern Michigan. In International Geoscience and Remote Sensing Symposium proceedings (pp. 2486-2489). IEEE. https://doi.org/10.1109/IGARSS.2010.5649435

\section{General rights}

Copyright and moral rights for the publications made accessible in the public portal are retained by the authors and/or other copyright owners and it is a condition of accessing publications that users recognise and abide by the legal requirements associated with these rights.

- Users may download and print one copy of any publication from the public portal for the purpose of private study or research.

- You may not further distribute the material or use it for any profit-making activity or commercial gain

- You may freely distribute the URL identifying the publication in the public portal 


\title{
K-BAND RADIO FREQUENCY INTERFERENCE SURVEY OF SOUTHEASTERN MICHIGAN
}

\author{
Shannon Curry ${ }^{1}$, Michael Ahlers ${ }^{2}$, Harvey Elliot ${ }^{1}$, Steve Gross ${ }^{1}$, Darren McKague ${ }^{1}$, Sidarth Misra ${ }^{1}$, John Puckett $^{1}$, Chris Ruf $^{1}$ \\ ${ }^{1}$ University of Michigan \\ 2455 Hayward St. \\ Ann Arbor, MI 48109-2143 USA \\ cruf@umich.edu \\ ${ }^{2}$ DTU Space \\ Technical University of Denmark \\ Orsteds Plads, Bldg. 348 \\ DK 2800 Kgs. Lyngby, DENMARK
}

\begin{abstract}
The Radio frequency Interference Survey of Earth (RISE) is a new type of instrument used to survey and characterize the presence of Radio Frequency Interference (RFI) that can affect microwave radiometers. It consists of a combined microwave radiometer and kurtosis spectrometer with broad frequency coverage and high temporal and spectral resolution. A K-Band airborne version has been built and flown across southeast Michigan. A kurtosis detector is included in RISE to reliably detect the presence of RFI, even at very low levels, and to aid in its characterization. A radiometer is included to measure the impact of the RFI on observed brightness temperature.
\end{abstract}

Keywords-microwave radiometer, radio
frequency interference

\section{INTRODUCTION}

Evidence of RFI has been identified at C-band and at Xband by the Advanced Microwave Scanning Radiometer (AMSR-E) ((e.g. Li et al., 2004) as well as WindSat. Additionally, AMSR-E has shown that K-band measurements are susceptible to RFI which are believed to be generated by both ground-based sources as well as the reflection by the earth's surface of signals from geostationary telecommunication satellites (e.g. Li et al., 2004; Li et al., 2006). In particular, observed RFI centered at $18.7 \mathrm{GHz}$ by AMSR-E and WindSat has significantly increased in 2008-2009 from 2005-2006 measurements. The RISE aircraft mission, operating over 18.7-19.3 GHz, will evaluate the K-band RFI environment in order to assess the optimal passband.

Section II will present an overview of the RISE radiometer hardware, followed by a description of the execution of the RISE flight campaign in Section III. A discussion of the RISE measurements and analysis will follow in Section IV. Finally, conclusions regarding the K-Band RFI environment over south-east Michigan will be discussed.

\section{INSTRUMENT DESCRIPTION}

The RISE spectrometer, built in collaboration with the Danish Technical University, is a total-power radiometer with a stepped local oscillator (LO) and a digital backend. A block diagram of the spectrometer is shown in Fig. 1. The spectrometer operates from 18.7 to $19.3 \mathrm{GHz}$ with a spectral resolution of $3.28 \mathrm{MHz}$ and a $200 \mathrm{~ms}$ integration time. The initial signal is fed to the radiometer through a horn antenna followed by the calibration switch, which alternates from the antenna to the warm load or the cold FET. The warm and cold loads track the stability of the radiometer and serve as calibration points for the raw second moment antenna counts. The horn antenna has a beamwidth of $20^{\circ}$ giving it a spatial resolution of approximately $1 \mathrm{~km}$ at an altitude of $8500 \mathrm{ft}$ (typical altitude for RISE flight).

There are 16 stepped LO frequencies covering 18.7-19.3 $\mathrm{GHz}$. The sequencing of radiometer measurement is shown in Fig. 2. The calibration switches to the cold FET, stepping through all $16 \mathrm{LO}$ frequencies and then switches to sampling through the antenna the same way. It then repeats this process by switching from the antenna to the warm load and then switching back to the antenna, stepping through all LO frequencies. The RISE digital back-end consists of a $\mathrm{X}$ bit $\mathrm{Y}$ Gsamples/sample ADC followed by a Xilinix Z FPGA clocked at A MHz. Digital subbanding occurs in the FPGA over 16 subbands. The FGPA measures higher order moments including the second moment which is proportional to power, and the 


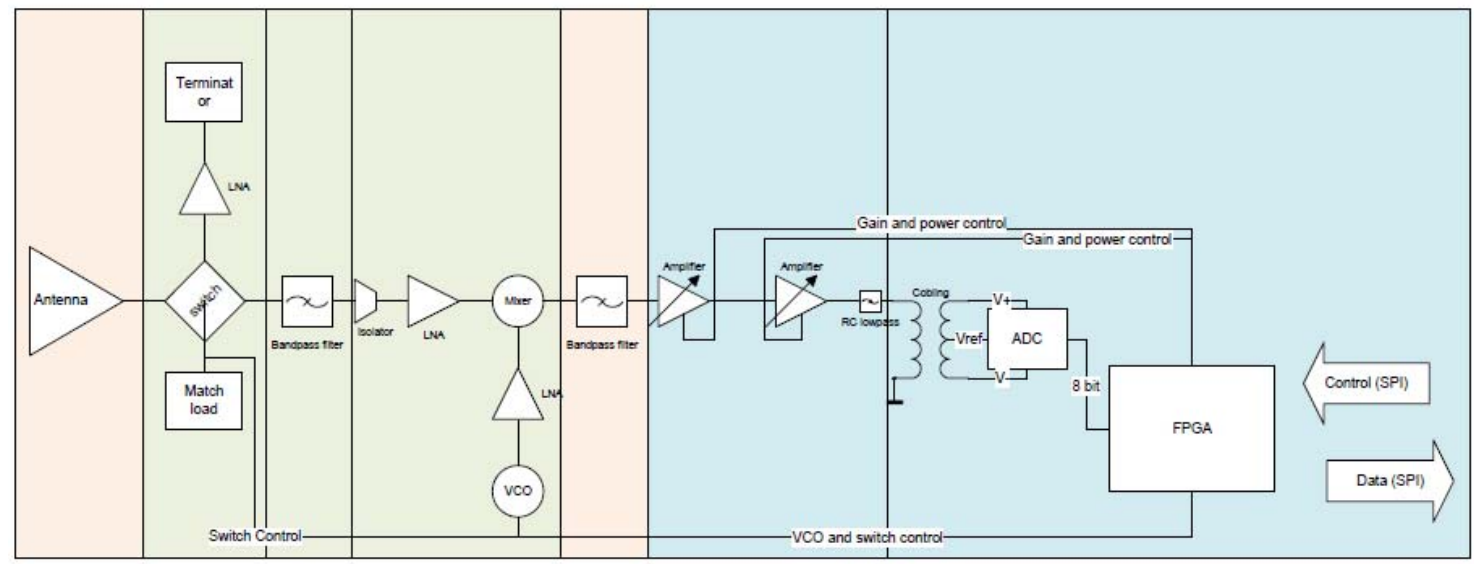

Figure 1: RISE functional block diagram

For a single TM data file (i.e. one loop through the Microcode Control Program), the timing looks like:

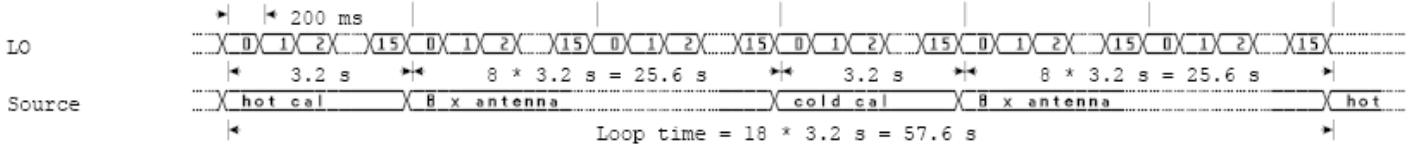

Within a single integration period, the timing looks like:

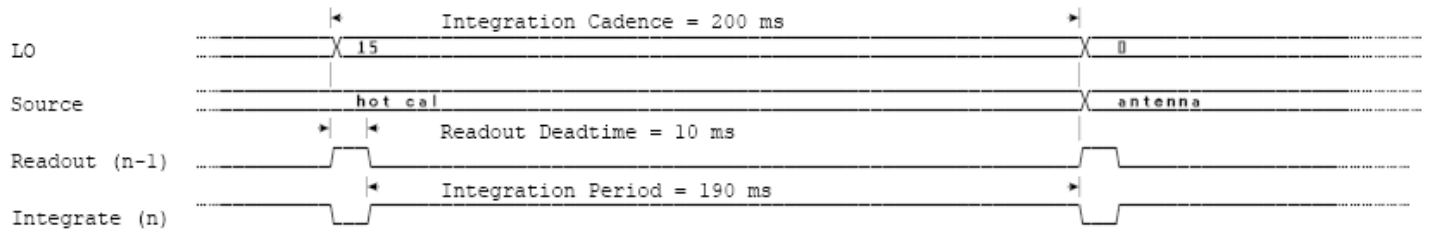

Figure 2: RISE timing diagram

fourth moment which with the second is used to compute the kurtosis of the signal. The kurtosis $(\mathrm{K})$ of a signal is defined by the fourth central moment divided by the square of the second central moment (e.g. Ruf et al., 2006):

$$
K=\frac{m_{4}}{m_{2}^{2}}
$$

where $m_{n}=\left\langle(v-\langle v\rangle)^{n}\right\rangle$ with $v$ defined by the predetected voltage.

\section{FLIGHT CAMPAIGN}

The RISE aircraft mission specifically targeted RFI due to telecommunication satellites operating at K-band. The incidence angle of the antenna was adjusted to view specular reflection from the DirecTV satellite located in Geoshynchronous with a sub-satellite point at around 100 degrees West longitude. Given the latitude $(\sim \mathrm{X} \mathrm{deg})$ and longitude $(\sim \mathrm{Y} \mathrm{deg})$ of the RISE flights and the curvature of the Earth, the required incidence angle is approximately $52 \mathrm{deg}$ with the antenna pointing $23 \mathrm{deg}$ (?) aft when the plane is flying due East. The RISE aircraft mission flew November 6th, 2009 on a Cessna 172 over Southeastern Michigan and along the Northern coast of Lake Huron (see Fig. 3).

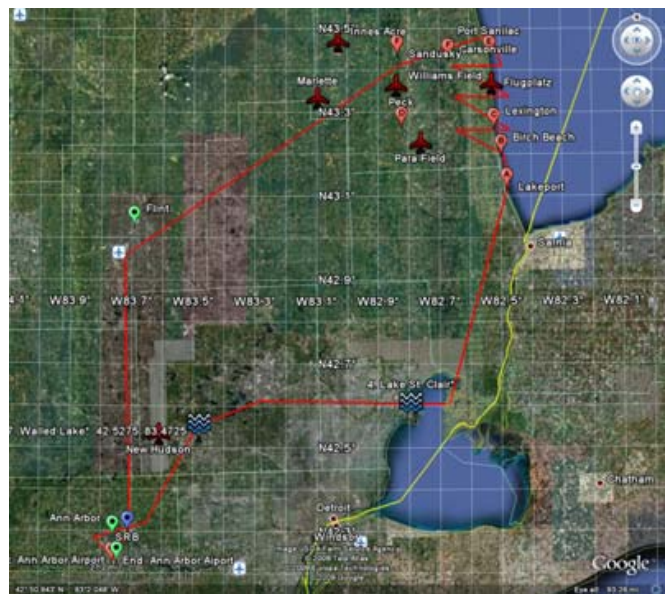

Figure 3: RISE Flight 


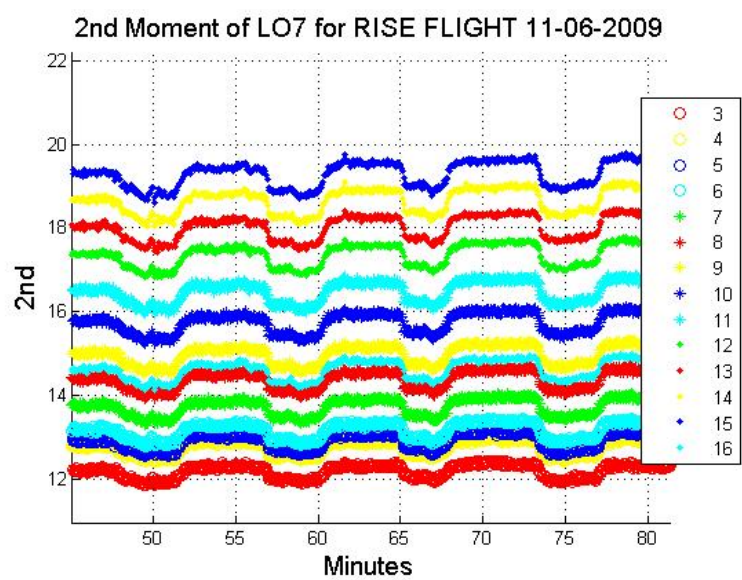

Figure 4: RISE raw 2nd moment time series over water crossings

Water crossings over Lake St. Clair and Lake Huron were used for brightness temperature (TB) calibration. Additional landmarks were selected for their diversity in surface topography. An RFI beacon was also installed above the Space Physics Research Building at the University of Michigan. It generated a continuous wave signal corresponding to a brightness temperature (TB) of $\mathrm{XX}$ at $19.0 \mathrm{GHz}$ as observed by RISE. .

\section{DATA ANALYSIS}

Water crossings during the flight were noted to verify the geolocation of the antenna footprint. As seen in Fig. 4, the water crossings, corresponding to the raster scans made over the western coast of Lake Huron, are sharply defined as a marked decrease in 2 nd moment counts.

Calibration of antenna temperatures was accomplished using the internal hot and cold loads as well as the water

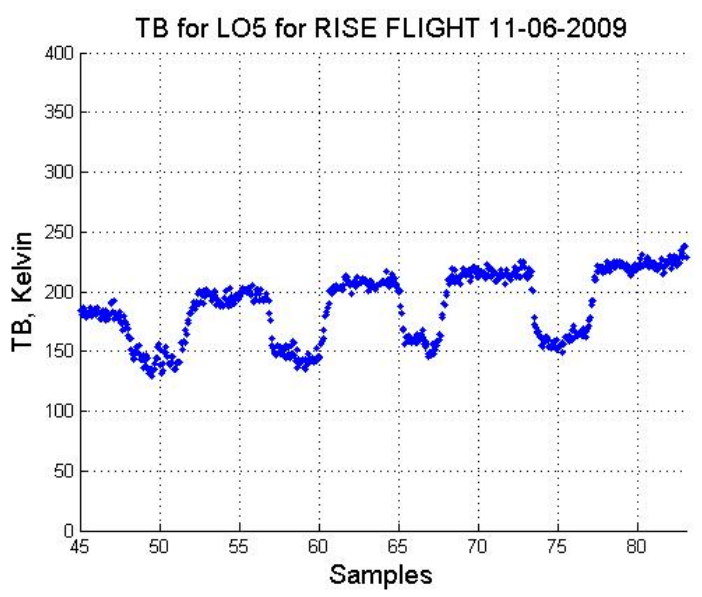

Figure 5: Calibrated Brightness Temperature(K) for the RISE mission, subband 8

crossings assuming a linear relationship between raw radiometer second moment counts and TB. For freshwater at a temperature of $8.3 \mathrm{C}$, the expected V-Pol brightness temperature at $19.0 \mathrm{GHz}(\mathrm{V}$-pol) would be $163.2 \mathrm{~K}$ (e.g. Klein et al., 1977). These antenna temperatures were converted to main beam TBs assuming a mainbeam efficiency of $83 \%$ and a side-lobe effective radiating temperature of $\mathrm{X}$.

RFI was observed over the Ann Arbor airport, the RFI beacon, Flint, MI and at lower levels over the western coast of Lake Huron. The Ann Arbor airport shows the highest range of pulsed RFI (Figure 6a) where kurtosis is above 3 in the first two minutes of the flight. The beacon clearly shows the CW generated signal, where the kurtosis is below 3 as also seen in Figure 6a. Over different LO frequencies, the kurtosis varies as seen in Figure $6 \mathrm{~b}$ and $6 \mathrm{c}$

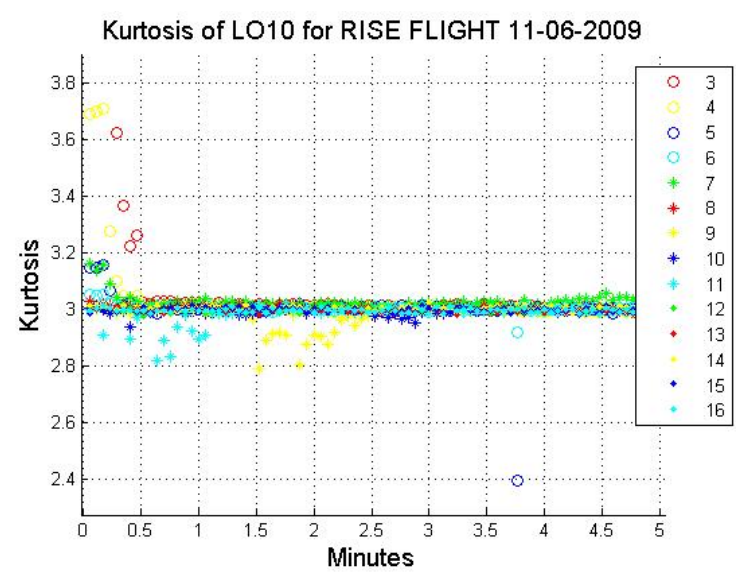

Figure 6: a) The initial minutes of the RISE flight 

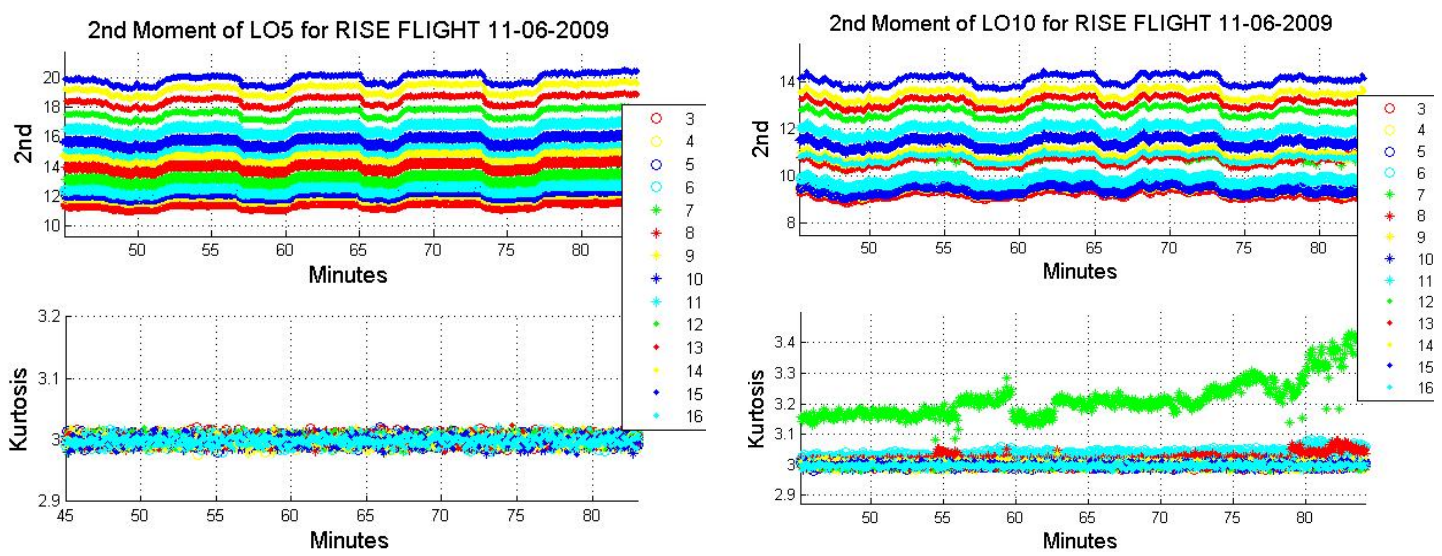

Figure 7, cont.: b) LO 5 raw second moment and kurtosis over 45-80 minutes after take-off c) LO 10 observed RFI over 45-80 minutes after take-off

\section{CONCLUSIONS}

The Radio frequency Interference Survey of Earth (RISE) is a new type of surveying tool that has identified RFI in the K-band. Future work for this survey will be critical in characterizing RFI generated from the reflection of geostationary satellites as well as identifying additional ground-based sources. The digitally filtered subbands will aid in future analysis in isolating specific frequencies where RFI occurs.

\section{ACKNOWLEDGEMENTS}

The authors would like to acknowledge the valuable assistance of D. Boprie, J. Peng, L. Marcoux (University of Michigan), and D. Kovach (Michigan Flyers).

\section{REFERENCES}

De Roo, R., S. Misra and C. Ruf (2007). "Sensitivity of the Kurtosis Statistic as a Detector of Pulsed Sinusoidal RFI," IEEE Trans. Geosci. Remote Sens., 45(7), 19381946.

Ellingson, S.W. and J.T. Johnson (2006). "A polarimetric survey of radio frequency interference in $\mathrm{C}$ - and $\mathrm{X}$ bands in the continental United States using WindSat radiometry," IEEE Trans. Geosc. Remote Sens., 44, 540-548.
Klein, L. A. and C. T. Swift, "An improved model for the dielectric constant of sea water at microwave frequencies," IEEE Trans. Ant. Prop., vol. AP-25, pp. 104-111,1977.

Li, L., et al. (2004). "A preliminary survey of radiofrequency interference over the U.S. in Aqua AMSR-E data," IEEE Trans. Geosci. Remote Sens., 42(2), 380380.

Li, L., P.W. Gaiser, and M. Bettenhausen (2006). "WindSat radio-frequency interference signature and its identification over land and ocean," IEEE Trans. Geosci. Remote Sens., 44(3), 530-539.

Misra, S. and Ruf, C.S. (2009). "Characterization of Lband RFI across the continental USA using a kurtosis detector," IGARSS 2009, Cape Town, South Africa

Misra, S., P.N. Mohammed, B. Guner, Ruf, C.S., J.R. Piepmeier and J.T. Johnson (2009). "Microwave radiometer radio frequency interference detection algorithms: A comparative study," IEEE Trans. Geosci. Remote Sens (in press)

Njoku E.G., P. Ashcroft, T.K. Chan, L. Li (2005). "Global survey and statistics of radio-frequency interference in AMSR-E land observations" IEEE Trans. Geosci. Remote Sens., 43(5), 938-947.

Ruf, C.S., S. M. Gross and S. Misra (2006). "RFI Detection and Mitigation for Microwave Radiometry with an Agile Digital Detector," IEEE Trans. Geosci. Remote Sens., 44(3), 694-706. 